GRADIATION\&APPLICATIONS

ISSN 2466-4294 (online) | rad-journal.org

Vol. 3 | Issue 2 | pp. 110-116, 2018

doi: 10.21175/RadJ.2018.02.018

Original research paper

\title{
RADIATION PROTECTION IN RADIOTHERAPY DEPENDS ON UNCERTAINTIES IN SMALL FIELD DOSIMETRY
}

\author{
Sonja Petkovska ${ }^{1^{*}}$, Margarita Ginovska², Hristina Spasevska², Yasin Acarbas ${ }^{1}$ \\ ${ }^{1}$ Faculty Radiotherapy and Oncology Department, Clinical Center Acibadem Sistina, Skopje, Macedonia \\ ${ }^{2}$ Faculty of Electrical Engineering and Information Technologies, Skopje, Macedonia
}

\begin{abstract}
Technological improvements in radiotherapy machines using small fields (SF) have improved mechanical accuracy and stability, as well as dosimetric control. Small fields are nonstandard radiation fields, for which reference dosimetry cannot be reliably performed using the existing protocols. Field size definition, difficulties of accurate measurements, modeling of SF dose calculations in Treatment Planning System (TPSs), calibration protocol establishing, reference condition achievements, are some of the challenges in SF Dosimetry. Small and Intensity Modulated Radiation Therapy (IMRT) field dosimetry can be very complex - large perturbation effects could make a significant impact on reference dosimetry procedures and output factors. Comparison between different detectors provides valuable information. The aim of this paper is to evaluate the differences of dose profiles and depth dose measured in the same conditions for standard and non-standard radiation fields. Measurements are performed using detectors with different sensitive volumes. Beam quality as well as symmetry and flatness are analyzed. Results from the measurements show that the differences for SF are obvious at the edge of the profiles and in the penumbra region, as well as in the build-up region into depth dose curves. To avoid the uncertainties, for static SF where reference conditions cannot be met and for IMRT fields where delivery conditions are far removed from calibration conditions, the new formalism should be implemented.
\end{abstract}

Key words: Beam quality, calibration, flatness, small field, symmetry

\section{INTRODUCTION}

Radiation therapy is a medical branch for malignant disease treatment using ionizing radiation. The linear accelerator is one of the most common devices in radiotherapy that produces photon and electron radiation beams, directs them to the patient, penetrates into body and irradiates certain volume. High quality radiotherapy treatment implies accurate and precise irradiation of the volume of interest with prescribed radiation dose and in the same time providing maximal protection of healthy organs along the path of ionizing radiation. Great and complicated technical preparation both of the patient and the equipment should be ensured in order to meet this medical requirement. Above all, pretreatment CT scan of patients is necessary in order to define the volume of interest to be irradiated, as well as to determine the exact coordinates for the administration of radiation treatment. The second requirement is to maintain mechanical and geometrical accuracy of the accelerator by which the treatment is being performed. The third requirement refers to dosimetric optimization which implies defining the benchmarks in the treatment planning system as initial conditions in the algorithm for isodose distribution calculation. Furthermore, these parameters are periodically checked and calibrated in order to minimize the uncertainty compared to reference data $[1,2]$.

According to international recommendations [3, 4], the measurement of dose profiles and depth dose curves should be strictly defined and maintained with the least possible deviation from the reference ones (Figure 1 and Figure 2).

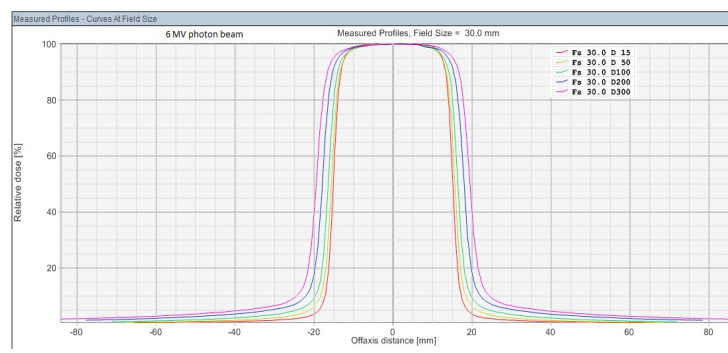

Figure 1. Dose profiles for $6 \mathrm{MV}$ photon beam measured at five different depths in water when the radiation field on the water surface was $3 \mathrm{~cm} \times 3 \mathrm{~cm}$

The analysis of parameters that should be undertaken is based on the quality of radiation beam determined by depth dose curves and symmetry, flatness and penumbra defined by dose profiles. The values of these parameters are directly related to the dose distribution in a given volume.

*pet.sonja@gmail.com 
S. Petkovska et al., Radiation protection in radiotherapy..., Rad. Applic., 2018, 3, 2, 110-116

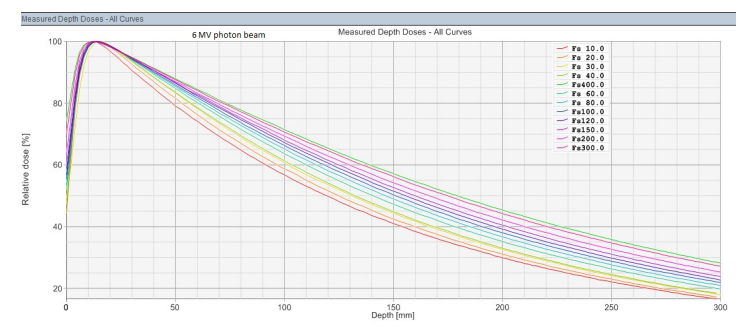

Figure 2. Depth dose distribution in water for different radiation fields

According to the recommendations of the International Atomic Energy Agency (IAEA) and American Association of Physics in Medicine (AAPM) [5-7], the quality of the photon radiation beam (Quality Index - QI) is defined for the field size $10 \mathrm{~cm} \times 10 \mathrm{~cm}$ at the phantom surface when SSD $=100 \mathrm{~cm}$. It can be expressed [7] by the equation (1):

$\mathrm{QI}=1.2661 * \mathrm{PDD}_{20,10}-0.0595$

where $\mathrm{PDD}_{20,10}$ is the ratio of the doses measured at depths of $20 \mathrm{~cm}$ and $10 \mathrm{~cm}$, expressed as percentages. It is defined

According to the International Electrotechnical Commission [8] - IEC, flatness is defined as the maximum percentage deviation $\left(\mathrm{D}_{\max }\right.$ in Figure 3$)$ of average dose along the central axis at $80 \%$ of the profile's width. The symmetry is defined as the percentage dose variation at two points $\mathrm{D}_{\text {left }}$ and $\mathrm{D}_{\text {right }}$ (Figure 3) of the dosing profile, spaced at equal distances from the left and right sides relative to the central axis.

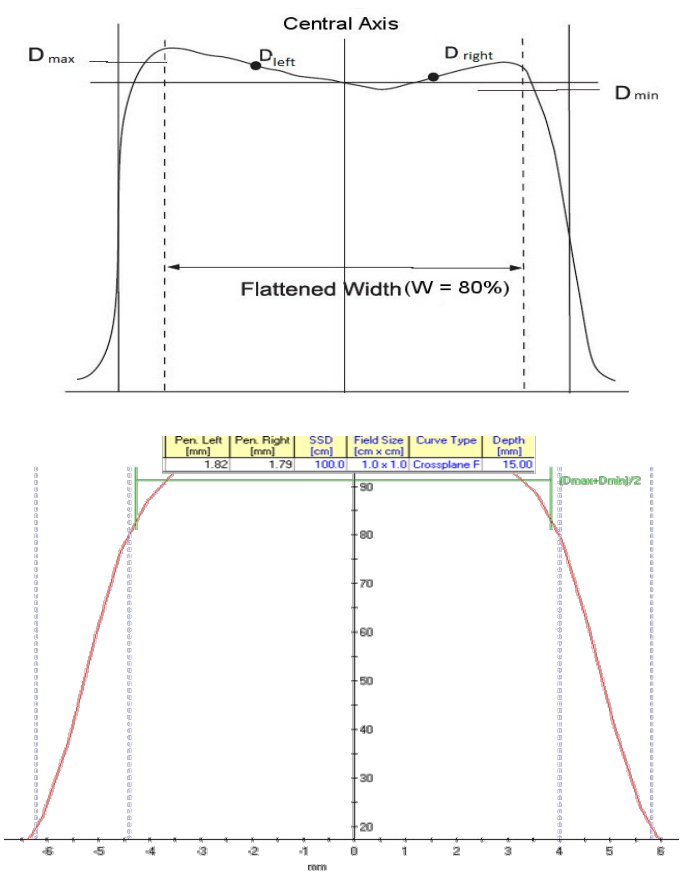

Figure 3. a) Dose profile shape; b) Penumbra definition

Physical penumbra is defined [4] as the lateral distance between two specific isodose curves at specific depths ( 2 dose points at the left or right field boundary expressed as the percentage of the central axis dose) between $80 \%$ and $20 \%$ of the dose on the central axis (Figure 3b).

The exact determination of these parameters in the treatment planning system is of a particular importance. They affect the calculated dose distribution.

The development of more sophisticated radiotherapy techniques during recent years, such as stereotactic radiotherapy and radio surgery, increases the requirements for higher accuracy in radiotherapy when small radiation fields are used. Studies show that standard detectors are not adequate to determine the parameters for small radiation fields. This paper presents the analysis of dose profiles and depth dose curve measurements performed under equal conditions with three different detectors, each of them with a different sensitive volume.

\section{EXPERIMENTAL}

\subsection{Description of equipment}

According to the international recommendation [7, 9], different kinds of dosimeters and electrometers properly calibrated in a primary or secondary laboratory could be used in radiotherapy. Measurements have been performed under clinical conditions, referring to $6 \mathrm{MV}$ photon radiation beam generated by a linear accelerator TRILOGY. Dosimetry equipment includes: water phantom, measuring detectors, electrometer and compatible software Mephysto (produced by PTW) [10, 11].

D1 detector (0.125 Semiflex Chamber Type 31010) is designed by PTW as a waterproof and fully guarded vented cylindrical ionization chamber, $6.5 \mathrm{~mm}$ length, with a nominal sensitive $0.125 \mathrm{~cm}^{3}$ volume. The wall of the sensitive volume is $0.55 \mathrm{~mm}$ PMMA $\left(1.19 \mathrm{~g} / \mathrm{cm}^{3}\right)$ and $0.15 \mathrm{~mm}$ graphite $\left(0.82 \mathrm{~g} / \mathrm{cm}^{3}\right)$. It is designed for measuring quantities in radiotherapy like absorbed dose to water, air kerma, or exposure.

D2 detector (Dosimetry Diode P Type 60016) is designed by PTW as a waterproof silicon detector, shielded, with a nominal sensitive volume of $0.03 \mathrm{~mm}^{3}$ ( $1 \mathrm{~mm}^{2}$ circular, $30 \mu \mathrm{m}$ thick). It can be used in air, solid state phantoms and in water for high energy photon beam dosimetry. The sensitive volume is diskshaped and perpendicular to the detector axis. The very high response $(175 \mathrm{nC} / \mathrm{Gy}$, versus $9 \mathrm{nC} / \mathrm{Gy}$ and $3.3 \mathrm{nC} / \mathrm{Gy}$ for $\mathrm{D} 3$ and $\mathrm{D} 1$ respectively) allows to measure beam profiles with very high resolution and very short dwell time.

D3 detector (Dosimetry Diode SRS Type 60018) is also PTW designed as a waterproof silicon detector, unshielded, disk-shaped perpendicular to the detector axis. Its outer diameter is $7 \mathrm{~mm}$ and the entrance window is $0.3 \mathrm{~mm} \mathrm{RW} 3,0.27 \mathrm{~mm}$ epoxy. The waterequivalent window thickness is $1.31 \mathrm{~mm}$ with total window area density of $140 \mathrm{mg} / \mathrm{cm}^{2}$. The sensitive volume is $0.3 \mathrm{~mm}^{3}\left(1 \mathrm{~mm}^{2}\right.$ circular $250 \mu \mathrm{m}$ thick). The SRS diode is with extremely high resolution. 
The TANDEM electrometer is a dual channel therapy electrometer designed for fast scanning measurements in the motorized water phantom with measuring intervals of $10 \mathrm{~ms}$. It is calibrated in electrical current (A) according to IEC 60731 with $10 \mathrm{fA}$ resolution. This dual channel device accepts ion chambers and solid state detectors to be connected. The chamber voltage for both channels is individually programmable in $50 \mathrm{~V}$ increments up to $400 \mathrm{~V}$ with reversible polarity. In conjunction with a TBA therapy beam analyzer, MEPHYSTO software controls TANDEM for fast and accurate beam data acquisition. A trigger input synchronizes measurements with external signals.

Water phantom $\mathrm{MP}_{3}$ is designed by PTW as a remote-controlled $3 \mathrm{D}$ acrylic water tank with $20 \mathrm{~mm}$ thick walls and a scanning range of $50 \times 50 \times 40.8 \mathrm{~cm}^{3}$, suitable for measuring radiation field sizes of up to 40 $\mathrm{cm} \times 40 \mathrm{~cm}$. The phantom comes complete with a highprecision electromechanical lifting carriage to allow its height adjustment; 3D moving mechanism driven by three calibration-free, high-speed stepper motors; as well as an electronic device (TBA Control Unit) for an automatic control of the detector position into the water phantom via $\mathrm{RS} 232$ interface. It provides detector positioning accuracy true to $0.1 \mathrm{~mm}$.

"MEPHYSTO $\mathrm{mc}^{2}$ " is a beam analyzing software for beam data acquisition and analysis with a PTW Water scanning system. It is equipped with all essential tools that allow performing dosimetry tasks related to accelerator commissioning as well as beam quality control.

\subsection{Description of measurements}

Measurements were performed by using three different detectors sequentially for several radiation fields (square fields from $1 \mathrm{~cm}^{2}$ to $100 \mathrm{~cm}^{2}$ ), under identical geometry of the system: linear accelerator water phantom - detector system. The photon beam leaves the accelerator gantry and shapes a certain radiation field on the water surface. Water phantom is placed directly under a photon radiation beam, the water surface is perpendicular to the direction of the radiation beam and source-skin-distance is $100 \mathrm{~cm}$. The detector is placed on the rail in the water phantom so that the geometrical center of the sensitive volume is matched with the radiation field center. D1 is positioned parallel to the water surface and D2, D3 are perpendicular. The rail has an automatically accommodated movement. The detector is forced to move according to pre-set conditions: in depth, along the central radiation beam in order to present the depth dose curve, or at a specific depth (50 mm or 100 $\mathrm{mm}$ ), perpendicular to the central radiation beam in order to present the dose profile representative for the certain depth.

The electrometer displays the signals from the irradiated detector in real time. This system is connected to the software (Figure 4) which processes the signals and calculates the values of the parameters of interest: symmetry, flatness, penumbra on the left and right side and quality of radiation beam. For the comparative analyses of the respective measurements, the curves obtained by different detectors referring to the same field and measuring depth are presented in the same graph.
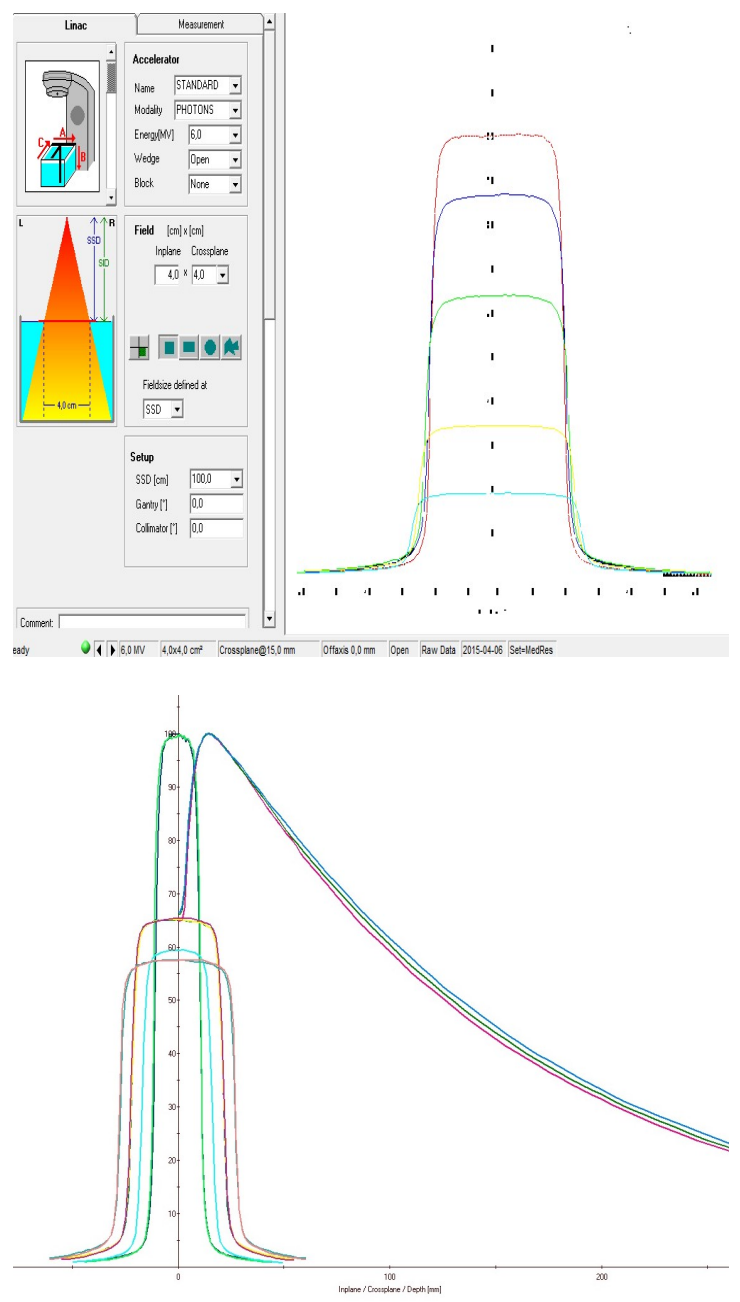

Figure 4. Software display of measurement results

\section{RESULTS AND DISCUSSION}

Measurements of dose profiles performed with three different detectors - D1, D2 and D3, are made for several radiation fields: $10 \mathrm{~cm} \times 10 \mathrm{~cm} ; 5 \mathrm{~cm} \times 5 \mathrm{~cm} ; 4$ $\mathrm{cm} \times 4 \mathrm{~cm}$; and $3 \mathrm{~cm} \times 3 \mathrm{~cm}, 2 \mathrm{~cm} \times 2 \mathrm{~cm}$ and $1 \mathrm{~cm} \times 1$ $\mathrm{cm}$, at two different depths in water $(5 \mathrm{~cm}$ and $10 \mathrm{~cm})$. Also, measurements of depth dose curves for the same radiation fields are performed.

Measuring parameters such as the quality of radiation beam, symmetry, flatness, and penumbra region are analyzed. Some of the results for dose profiles and penumbras are shown in Figure 5 to Figure 8. The measured values with three different detectors for the depth dose - the quality of radiation beam, dose profile for standard fields and dose profile for small radiation fields are presented in Table 1 , Table 2 and Table 3, respectively. 
S. Petkovska et al., Radiation protection in radiotherapy..., Rad. Applic., 2018, 3, 2, 110-116

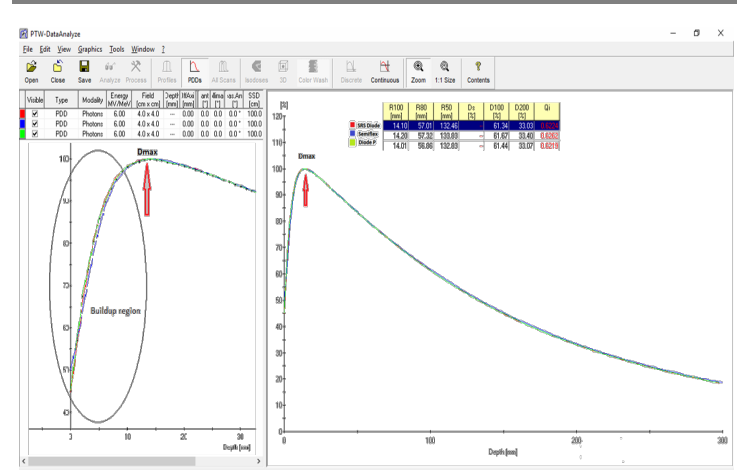

Figure 5. Depth dose distribution for radiation field $4 \mathrm{~cm} \times 4 \mathrm{~cm}$, measured by three different detectors

Figure 5 shows the depth dose curves relating to $4 \mathrm{~cm} \times 4 \mathrm{~cm}$ radiation field. There are almost no deviations and the quality of radiation beam has been observed, irrespective of the measuring detector used for measuring of depth dose curves.

Table 1. Depth dose - Quality of radiation beam

\begin{tabular}{|c|c|c|c|c|c|c|}
\hline \multirow[b]{2}{*}{$\begin{array}{c}\text { Photons } \\
6 \mathrm{MV}\end{array}$} & \multicolumn{6}{|c|}{ Depth dose -Quality of radiation beam (QI) } \\
\hline & $\begin{array}{c}10 \mathrm{~cm} \\
x \\
10 \mathrm{~cm}\end{array}$ & $\begin{array}{c}5 \mathrm{~cm} \\
\mathrm{x} \\
5 \mathrm{~cm}\end{array}$ & $\begin{array}{c}4 \mathrm{~cm} \\
\mathrm{x} \\
4 \mathrm{~cm}\end{array}$ & $\begin{array}{c}3 \mathrm{~cm} \\
\mathrm{x} \\
3 \mathrm{~cm}\end{array}$ & $\begin{array}{c}2 \mathrm{~cm} \\
\mathrm{x} \\
2 \mathrm{~cm}\end{array}$ & $\begin{array}{c}1 \mathrm{~cm} \\
\mathrm{x} \\
1 \mathrm{~cm}\end{array}$ \\
\hline $\begin{array}{l}\mathrm{PDD}_{20 / 10} \\
\text { D1: } \\
\text { QI }\end{array}$ & $\begin{array}{l}0.575 \\
0.670\end{array}$ & 0.554 & 0.546 & 0.545 & 0.53 & 0.534 \\
\hline $\begin{array}{l}\mathrm{PDD}_{20 / 10} \\
\text { D2: } \\
\text { QI }\end{array}$ & $\begin{array}{l}0.575 \\
0.669\end{array}$ & 0.553 & 0.545 & 0.541 & 0.532 & 0.537 \\
\hline $\begin{array}{l}\text { PDD }_{20 / 10} \\
\text { D3: } \\
\text { QI }\end{array}$ & $\begin{array}{l}0.570 \\
0.667\end{array}$ & 0.554 & 0.542 & 0.541 & 0.532 & 0.536 \\
\hline
\end{tabular}

It could be concluded from the depth dose analyzes presented in Table 1 that the quality of the radiation beam is constant for particular field size, irrespective of the used detector. The differences appear only in the "build-up" region, for depth doses smaller than the depth of dose maximum (Figure 5).

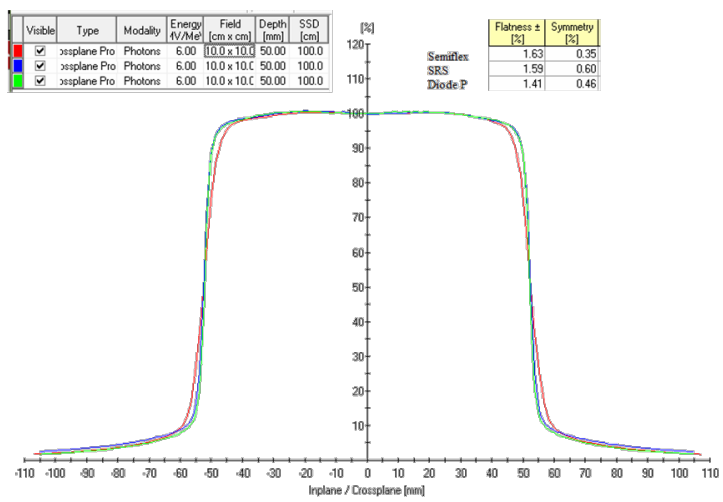

Figure 6. Dose profiles of $10 \mathrm{~cm}$ x10 $\mathrm{cm}$ radiation field measured by three different detectors

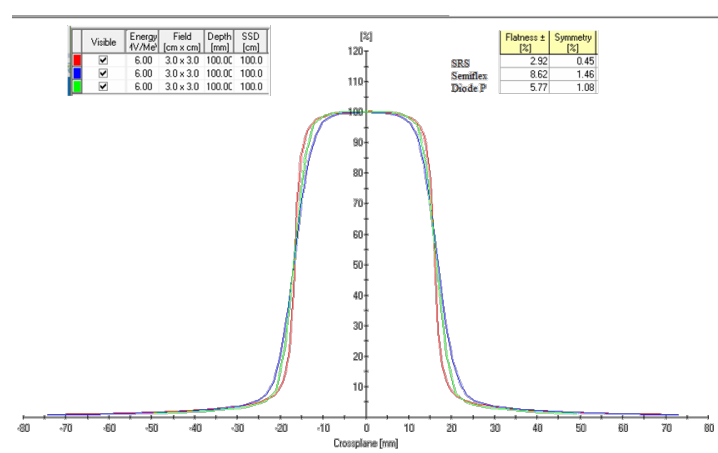

Figure 7. Dose profile of $3 \mathrm{~cm} \times 3 \mathrm{~cm}$ radiation field measured by three different detectors

Dose profiles performed at $5 \mathrm{~cm}$ depth in water, relating to $10 \mathrm{~cm} \times 10 \mathrm{~cm}$ radiation field, measured by the three detectors in series, are presented in Figure 6. Strong concurrence between the curves can also be visually observed. The differences in symmetry and flatness values measured with three detectors respectively are negligible. Figure 7 presents the dose profiles obtained by three detectors in series at $10 \mathrm{~cm}$ depth in water for a small $(3 \mathrm{~cm} \times 3 \mathrm{~cm})$ radiation field. There is a significant difference between the curves, especially relating to the profile measured by D1, particularly at points at the radiation field's edges and the penumbra region. This is a result of the fact that the smaller the distance from the central beam to the field's edge, the smaller the distance to which the scattered (secondary) electrons can "travel" so that the equilibrium of scattered electrons has been disturbed $[12 ; 13]$. Also, there are great deviations in measured parameters relating to this detector (Table 3), because the sensitive volume of detector D1 is the greatest one.

Comparison of the measured parameters for the standard field sizes indicates a strong matching of the dose profiles, as well as an insignificant difference in the measurement parameters referring to the same radiation field. For smaller radiation fields, the differences are getting greater.

Table 2. Dose profile for standard fields

\begin{tabular}{|c|c|c|c|c|}
\hline \multirow{2}{*}{$\begin{array}{c}\text { Photons } \\
6 \mathrm{MV}\end{array}$} & \multicolumn{2}{|c|}{$\begin{array}{c}\text { Measured parameters } \\
\text { for field } \\
5 \mathrm{~cm} \times \mathrm{cm}\end{array}$} & \multicolumn{2}{|c|}{$\begin{array}{c}\text { Measured parameters } \\
\text { for field } \\
\text { 10 cm x 10 cm }\end{array}$} \\
\cline { 2 - 5 } & $\begin{array}{c}\text { Symmetry } \\
(\%)\end{array}$ & $\begin{array}{c}\text { Flatness } \\
(\%)\end{array}$ & $\begin{array}{c}\text { Symmetry } \\
(\%)\end{array}$ & $\begin{array}{c}\text { Flatness } \\
(\%)\end{array}$ \\
\hline $\begin{array}{c}\mathrm{D} 1 \\
(\mathrm{~d}=5 \mathrm{~cm})\end{array}$ & 0.82 & 0.36 & 0.36 & 1.63 \\
\hline $\begin{array}{c}\mathrm{D} 1 \\
(\mathrm{~d}=10 \mathrm{~cm})\end{array}$ & 0.96 & 0.36 & 0.44 & 1.73 \\
\hline $\begin{array}{c}\mathrm{D} 2 \\
(\mathrm{~d}=5 \mathrm{~cm})\end{array}$ & 0.86 & 1.61 & 0.46 & 1.41 \\
\hline $\begin{array}{c}\mathrm{D} 2 \\
(\mathrm{~d}=10 \mathrm{~cm})\end{array}$ & 0.51 & 1.63 & 0.46 & 1.41 \\
\hline $\begin{array}{c}\mathrm{D} 3 \\
(\mathrm{~d}=5 \mathrm{~cm})\end{array}$ & 0.51 & 1.51 & 0.51 & 1.31 \\
\hline $\begin{array}{c}\mathrm{D} 3 \\
(\mathrm{~d}=10 \mathrm{~cm})\end{array}$ & 0.66 & 1.56 & 0.45 & 1.32 \\
\hline
\end{tabular}


S. Petkovska et al., Radiation protection in radiotherapy..., Rad. Applic., 2018, 3, 2, 110-116

Table 3. Dose profile for small radiation fields

\begin{tabular}{|c|c|c|c|c|}
\hline \multirow{2}{*}{$\begin{array}{c}\text { Photons } \\
6 \mathrm{MV}\end{array}$} & \multicolumn{2}{|c|}{$\begin{array}{c}\text { Measured parameters } \\
\text { for field } \\
\text { 4cm x 4 cm }\end{array}$} & \multicolumn{2}{|c|}{$\begin{array}{c}\text { Measured parameters } \\
\text { for field } \\
3 \mathrm{~cm} \times 3 \mathrm{~cm}\end{array}$} \\
\cline { 2 - 5 } & $\begin{array}{c}\text { Symmetry } \\
(\%)\end{array}$ & $\begin{array}{c}\text { Flatness } \\
(\%)\end{array}$ & $\begin{array}{c}\text { Symmetry } \\
(\%)\end{array}$ & $\begin{array}{c}\text { Flatness } \\
(\%)\end{array}$ \\
\hline $\begin{array}{c}\mathrm{D} 1 \\
(\mathrm{~d}=5 \mathrm{~cm})\end{array}$ & 0.98 & 5.93 & 0.95 & 10.6 \\
\hline $\begin{array}{c}\mathrm{D} 1 \\
(\mathrm{~d}=10 \mathrm{~cm})\end{array}$ & 1.4 & 6.06 & 1.19 & 10.77 \\
\hline $\begin{array}{c}\mathrm{D} 2 \\
(\mathrm{~d}=5 \mathrm{~cm})\end{array}$ & 0.64 & 2.12 & 1.18 & 8.99 \\
\hline $\begin{array}{c}\mathrm{D} 2 \\
(\mathrm{~d}=10 \mathrm{~cm})\end{array}$ & 0.42 & 2.34 & 2.76 & 8.28 \\
\hline $\begin{array}{c}\mathrm{D} 3 \\
(\mathrm{~d}=5 \mathrm{~cm})\end{array}$ & 0.28 & 1.84 & 0.18 & 4.52 \\
\hline $\begin{array}{c}\mathrm{D} 3 \\
(\mathrm{~d}=10 \mathrm{~cm})\end{array}$ & 0.35 & 2.17 & 0.52 & 4.63 \\
\hline
\end{tabular}

Table 4. Dose profile for small radiation fields

\begin{tabular}{|c|c|c|c|c|}
\hline $\begin{array}{c}\text { Photons } \\
6 \mathrm{MV}\end{array}$ & \multicolumn{2}{|c|}{$\begin{array}{c}\text { Measured parameters } \\
\text { for field } \\
\text { 2 cm x 2 cm }\end{array}$} & \multicolumn{2}{|c|}{$\begin{array}{c}\text { Measured parameters } \\
\text { for field } \\
\text { cm x1 cm }\end{array}$} \\
\hline & $\begin{array}{c}\text { Symmetry } \\
(\%)\end{array}$ & $\begin{array}{c}\text { Flatness } \\
(\%)\end{array}$ & $\begin{array}{c}\text { Symmetry } \\
(\%)\end{array}$ & $\begin{array}{c}\text { Flatness } \\
(\%)\end{array}$ \\
\hline $\begin{array}{c}\mathrm{D} 1 \\
(\mathrm{~d}=5 \mathrm{~cm})\end{array}$ & 0.95 & 10.6 & 2.89 & 14.88 \\
\hline $\begin{array}{c}\mathrm{D} 1 \\
(\mathrm{~d}=10 \mathrm{~cm})\end{array}$ & 1.19 & 10.77 & 4.72 & 15.10 \\
\hline $\begin{array}{c}\mathrm{D} 2 \\
(\mathrm{~d}=5 \mathrm{~cm})\end{array}$ & 1.18 & 8.99 & 2.44 & 10.73 \\
\hline $\begin{array}{c}\mathrm{D} 2 \\
(\mathrm{~d}=10 \mathrm{~cm})\end{array}$ & 2.76 & 8.28 & 2.94 & 11.65 \\
\hline $\begin{array}{c}\mathrm{D} 3 \\
(\mathrm{~d}=5 \mathrm{~cm})\end{array}$ & 0.18 & 4.52 & 0.61 & 8.88 \\
\hline $\begin{array}{c}\mathrm{D} 3 \\
(\mathrm{~d}=10 \mathrm{~cm})\end{array}$ & 0.52 & 4.63 & 1.14 & 9.22 \\
\hline
\end{tabular}

Table 5. Penumbra measured by Diode P detector

\begin{tabular}{|l|l|l|l|l|l|l|l|}
\hline $\begin{array}{l}\text { Field } \\
\text { size } \\
\text { Depth }\end{array}$ & $10 \times 10$ & $8 \times 8$ & $6 \times 6$ & $4 \times 4$ & $3 \times 3$ & $2 \times 2$ & $1 \times 1$ \\
\hline $50 m m$ & 3.25 & 3.6 & 3.45 & 3.26 & 3.11 & 3.03 & 2.83 \\
\hline $100 \mathrm{~mm}$ & 4.2 & 3.9 & 3.63 & 3.36 & 3.39 & 3.22 & 3.02 \\
\hline
\end{tabular}

Measuring parameters referring to dose profiles, symmetry and flatness of small radiation fields depend on the applied detector. According to the results that can be found in available literature $[14,15,16]$, the smaller radiation field, the greater the influence of the sensitive volume's size of measuring detector upon the result.

If we analyze penumbra $80-20 \%$ obtained from one detector presented in Table 4 , it is obvious that the penumbra dimension is dependent on the field size and the depth of the profile. Penumbra is as small as the field size is, and as small as the measuring depth is.

Dose profiles for the same radiation field size, obtained at the same depth, show that the penumbra dimension depends on the detector type. Detector 1 (D1) always presents the biggest penumbra and detector 3 (D3) presents the smallest one. Penumbra differences for the $3 \times 3$ radiation field are presented in Figure 8.

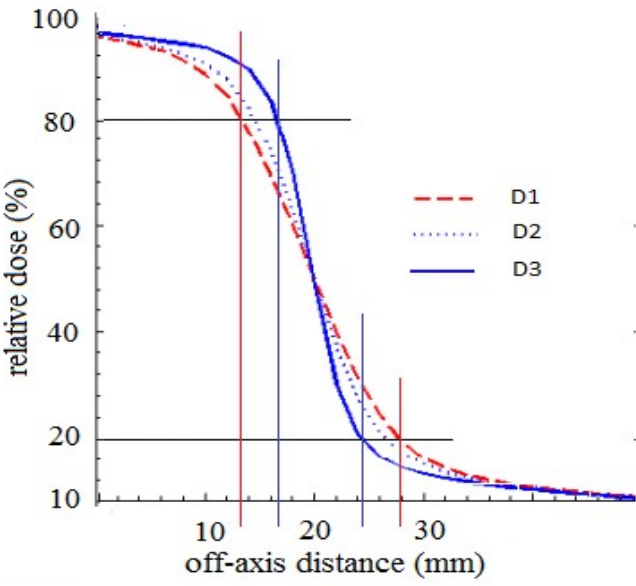

Figure 8. Penumbras for $3 \times 3 \mathrm{~cm}$ radiation field measured by three different detectors

The three detectors analyzed in this paper are largely similar. They are all invented by same manufacturer and are recommended for radiotherapy measurements. For standard dimensions of the radiation fields used in conventional radiotherapy, there are no significant differences in the curves performed with different detectors. By reducing the dimensions of the radiation field below $4 \mathrm{~cm}$, the length of the first detector (D1) becomes comparable to the dimension of the radiation field. Means, the length of $6.5 \mathrm{~mm}$ is placed centrally in a field of $1 \mathrm{~cm}$ or $2 \mathrm{~cm}$ width. The diodes (D2 and D3 detectors) have a crosssectional area of $1 \mathrm{~mm}^{2}$, which means that the diameter of $1.1 \mathrm{~mm}$ is centrally positioned in the radiation field. This explains the difference in the shape of the profile curves to the edges of the small field and in the penumbra region.

Table 6. Differences in penumbra measured with different detectors

\begin{tabular}{|c|c|c|c|c|c|c|c|}
\hline \multicolumn{2}{|c|}{$\begin{array}{c}\text { Field sixe } \\
\left(\mathrm{cm}^{2}\right)\end{array}$} & $1 \times 1$ & $2 \times 2$ & $3 \times 3$ & $4 \times 4$ & $5 \times 5$ & $10 \times 10$ \\
\hline \multirow{3}{*}{$\Delta_{\text {left }}$} & $(\mathrm{mm})$ & 0.99 & 2.04 & 3.6 & 3.64 & 3.62 & 3.67 \\
\cline { 2 - 8 } & $(\%)$ & 9.9 & 10.2 & 12 & 9.1 & 7.2 & 3.67 \\
\hline \multirow{3}{*}{$\Delta_{\text {right }}$} & $(\mathrm{mm})$ & 1.04 & 2.18 & 3.52 & 3.69 & 3.6 & 3.79 \\
\cline { 2 - 8 } & $(\%)$ & 10.4 & 10.9 & 11.7 & 9.2 & 7.2 & 3.79 \\
\hline
\end{tabular}

The absolute values of these differences are not dramatically big (table $5, \Delta_{\text {left }}$ and $\Delta_{\text {right }}$ in $\mathrm{mm}$ ), but it should be taken into consideration that the $3 \mathrm{~mm}$ difference for the $10 x 10$ field is $3 \%$ of the radiation field dimension and just a $1 \mathrm{~mm}$ difference for the $1 \mathrm{x} 1$ field is $10 \%$ of that radiation field dimension. This is one more reason why a smaller volume detector should be used for small field dosimetry. The accuracy of penumbral measurements in radiotherapy is very important.

Dose planning computers require accurate data to adequately model beams which are used to calculate 
S. Petkovska et al., Radiation protection in radiotherapy..., Rad. Applic., 2018, 3, 2, 110-116

patient dose distributions. Smaller detectors, having spatial resolutions as low as $1 \mathrm{~mm}$, provide minimal error for the penumbra dose assessment.

\section{CONCLUSIONS}

This paper presents the accuracy of dose profiles and depth dose measurements for standard and nonstandard radiation fields.

Measurements and analysis of the quality of radiation beam show that it is constant for a particular field size, irrespective of the used detector. The differences appear only in the "build-up" region, for depth doses smaller than the depth of dose maximum.

Measuring parameters referring to dose profiles, symmetry and flatness of small radiation fields depend on the applied detector. Dose profiles for the same radiation field size, obtained at the same depth, show that the penumbra dimension depends on the detector type. Penumbra is as small as the field size, and as small as the measuring depth. The absolute values of these differences are not huge, but if we consider the differences versus the field size, the relative values of the differences should become up to $10 \%$ and more.

The measurements and analysis presented in the paper lead to the conclusion that a smaller volume of the measuring detector provides more accurate signals in the penumbra region, and the volume effect is negligible when the detector's size is several times smaller than the size of the radiation field.

As the size of the sensitive volume of the measuring detector directly affects the parameters of small radiation fields ( $4 \mathrm{~cm} \mathrm{x} 4 \mathrm{~cm}$ and smaller), dosimetry for standard radiation fields is not sufficient. In this case, dosimetry of small fields could be implemented, which is not typical for standard radiant fields

Ensuring accurate measurement of dose distribution for small fields (especially at the radiation field's edges and the penumbra region) is a particular interest of contemporary radiotherapy techniques such as stereotactic radiotherapy and radiosurgery, given the fact that the whole radiation treatment is conducted using small fields. When carrying out this treatment, a number of small fields at different angles were used, so the contribution of each field has been superposed into their penumbra regions. For the fields smaller than $3 \mathrm{~cm}$, the field is practically composed merely of penumbra. The distance between $80 \%$ and $20 \%$ dose is very small. It increases the isodose curve and volume effects in the penumbra region.

Therefore, in order to avoid major uncertainties, dose profiles and depth dose curves of small fields should be measured by a detector with a small sensitive volume. Dosimetric uncertainties in small field dosimetry include many other factors important for accurate measurements. International standards regarding dosimetry of small fields are developing permanently and different uncertainties in small field dosimetry are still the subject of scientific research.

\section{REFERENCES}

1. F. M. Khan, The Physics of Radiation Therapy, 3rd ed., Philadelphia (PA), USA: Lippincott Williams \& Wilkins, 2003.

Retrieved from: https://ucrfisicamedica.files.wordpress .com/2010/10/phys-of-radiation-therapy-3-edicionkhan.pdf;

Retrieved on: Aug. 14, 2018

2. E. B. Podgorsak, Radiation Physics for Medical Physicists, 2nd ed., Berlin, Germany: Springer-Verlag Berlin Heidelberg, 2006.

DOI: 10.1007/978-3-642-00875-7

3. Comprehensive QA for Radiation Oncology, Rep. 46, AAPM, Alexandria (VA), USA, 1994.

Retrieved from: https://www.aapm.org/pubs/reports/ RPT 46.PDF;

Retrieved on: Aug. 18, 2018

4. AAPM code of practice for radiotherapy accelerators: Reports of AAPM radiation therapy, Rep. 47, AAPM, Alexandria (VA), USA, 1994.

Retrieved from: https://aapm.onlinelibrary.wiley.com/ doi/abs/10.1118/1.597398;

Retrieved on: Aug. 18, 2018

5. Protocol for Clinical Reference Dosimetry of HighEnergy Photon and Electron Beams, Rep. 67, AAPM Alexandria (VA), USA, 1999.

Retrieved from: https://www.aapm.org/pubs/reports/ RPT 67.pdf;

Retrieved on: Aug. 18, 2018

6. Dosimetry of High-Energy Photon Beams based on Standards of Absorbed Dose to Water, ICRU Report 64, ICRU, Bethesda (MD), USA, 2000.

Retrieved from: https://www.tandfonline.com/doi/pdf/ $10.1080 /$ j.1600-

0455.2002.4306211.x?needAccess $=$ true

Retrieved on: Aug. 18, 2018

7. Absorbed dose determination in external beam radiotherapy, IAEA TRS-398, IAEA, Austria, Vienna, 2006.

Retrieved from: http://naweb.iaea.org/nahu/DMRP/do cuments/CoP_V12_2006-06-05.pdf;

Retrieved on: May 3, 2018

8. Particular Requirements for the safety of Electron Accelerators in the Range $1 \mathrm{MeV}$ to $5 \mathrm{OMeV}$, IEC 606012-1, International Electrotechnical Commission, Switzerland, Geneva, Jun. 30, 1998.

9. Calibration of reference dosimeters for external beam radiotherapy, IAEA TRS-469, IAEA, Austria, Vienna, 2009.

Retrieved from:

http://pub.iaea.org/MTCD/publications/PDF/trs469 web.pdf

Retrieved on: May 3, 2018

10. PTW products for radiation therapy, PTW, Freiburg, Germany, 2018.

Retrieved from: http://www.ptwusa.com/radiation therapy.html? \&cId $=3279$; Retrieved on: May 3, 2018

11. Absorbed Dose Determination in Small Fields for High Energy Photon Beams, PTW, Freiburg, Germany, 2014. Retrieved from:

https://www.ptw.de/typo3conf/ext/naw securedl/secu re.php? $\mathrm{u}=0 \&$ file $=$ ZmlsZWFkbWluL2ludGVybmFscygy YWRfdGhlcmFweS9BYnNvcmJlZF9Eb3NlXoRldGVyb WluYXRpb25fU21hbGxfRmllbGRzXo5vdGVfZW5fNTY wMjEwMDNfMDIucGRm\&t=1528631687\&hash=05a8f c5510cf 429395 f4bb1d8250736d

Retrieved on: May 3, 2018

12. J. Herzen, M. Todorovic, F. Cremers, D. Albers, R. Schmidt, "Dosimetric Evaluation of a 2D pixel ionization chamber for implementation in clinical routine," Phy. Med. Biol., vol. 52, no. 4, pp. 1197 1208, Feb. 2007. 
DOI: $10.1088 / 0031-9155 / 52 / 4 / 023$ PMid: 17264380

13. A. J. D. Scott et al., "Characterizing the influence of detector density on dosimeter response in nonequilibrium small photon fields," Phys. Med. Biol., vol. 57, no. 14, pp. 4461 - 4476, Jun. 2012. DOI: $10.1088 / 0031-9155 / 57 / 14 / 4461$ PMid: 22722374

14. M. M. Aspradakis et al., Small Field MV Photon Dosimetry, Rep. 103, IPEM, York, UK, 2010.

Retrieved from: https://inis.iaea.org/collection/NCLCo llectionStore/ Public/42/026/42026419.pdf; Retrieved on: Aug. 18, 2018
15. D. Cyarnecki, K. Zink, "Monte Carlo calculated correction factors for diodes and ion chambers in small photon fields," Phys. Med. Biol., vol. 58, no. 8, pp. 2431 - 2444, Apr. 2013.

DOI: 10.1088/o031-9155/58/8/2431

PMid: 23514734

16. P. Francescon et al., "Calculation of $\mathrm{k}(\mathrm{Q}$ (clin), $\mathrm{Q}(\mathrm{msr}))(\mathrm{f}(\mathrm{clin}), \mathrm{f}(\mathrm{msr}))$ for several small detectors and for two linear accelerators using Monte Carlo simulations," Med. Phys., vol. 38,no. 12, pp. $6513-$ 6527, Dec. 2011.

DOI: $10.1118 / 1.3660770$

PMid: 22149834 